Sādhanā Vol. 38, Part 6, December 2013, pp. 1357-1368. (C) Indian Academy of Sciences

\title{
Luminaries-level structure improvement of LEDs for heat dissipation enhancement under natural convection
}

\author{
KE WU ${ }^{1}$, LE WANG ${ }^{1,2}$, YI-BO YU ${ }^{1}$, ZHI-YI HUANG ${ }^{1, *}$ and \\ PEI LIANG ${ }^{2}$
}

${ }^{1}$ Zhejiang University, Hangzhou, 310027, China

${ }^{2}$ China Jiliang University, Hangzhou, 310018, China

e-mail: hzy@zju.edu.cn

MS received 18 January 2011; revised 20 May 2013; accepted 5 June 2013

\begin{abstract}
Heat dissipation enhancement of LED luminaries is of great significance to the large-scale application of LED. Luminaries-level structure improvement by the method of boring through-hole is adopted to intensify heat dissipation. Furthermore, the natural convection heat transfer process of LED luminaries is simulated by computational fluid dynamics (CFD) model before and after the structural modification. As shown by computational results, boring through-hole is beneficial to develop bottomto-top natural convection, eliminate local circumfluence, and finally form better flow pattern. Analysis based on field synergy principle shows that boring through-hole across LED luminaries improves the synergy between flow field and temperature field, and effectively decreases the thermal resistance of luminaries-level heat dissipation structure. Under the same computational conditions, by luminaries-level structure improvement the highest temperature of heat sink is decreased by about $8^{\circ} \mathrm{C}$ and the average heat transfer coefficient is increased by $45.8 \%$.
\end{abstract}

Keywords. LED; computational fluid dynamics; luminaire; field synergy; natural convection.

\section{Introduction}

Due to its significant advantages such as high efficiency, long lifetime, low power consumption, inconceivable controllability and high reliability, light-emitting diode (LED) is believed to replace conventional, inherently less efficient incandescent and fluorescent light sources (Schubert \& Kim 2005). However, till now LED chip can only convert $20 \%$ of the input power into light while the rest $80 \%$ is converted into heat, which will cause the junction temperature of

*For correspondence 
LED chips to rise substantially. The rise of junction temperature has great impact on the performance of LED. High junction temperature lowers the overall efficiency of LED device, lowers forward voltage, causes emission to shift to longer wavelengths, and reduces device lifetime and reliability. Furthermore, a rise in phosphor's temperature reduces the quantum efficiency thus reducing lumen output (Arik et al 2007). However, in order to generate enough lumen output, the driving current of LED chips increasing fast recently, which makes it more and more difficult to keep LED junction temperature at low level. At present, the heat flux of power LED has exceeded $100 \mathrm{~W} / \mathrm{cm}^{2}$. Heat dissipation has become one of the key problems limiting the large scale application of LED.

Although some of costly heat dissipation technologies, such as miniature vapor-compression refrigerator (Luo et al 2007), thermoelectric or piezoelectric cooler (Acikalin et al 2004), and micro channel heat radiator, are able to reject heat efficiently, they may make LED less competitive in the market. Furthermore, most existent efficient heat dissipation technologies, which inevitably utilize moving mechanical components, such as pump, compressor, fan, etc., damage LED's advantage of long lifetime. That is the reason why natural convection is still an important trouble-free solution to LED devices. Due to its low heat transfer coefficient, natural convection heat dissipation system requires large surface area, which is always limited by practical application environment. Therefore, much research has been done internationally to increase natural convection heat transfer coefficient, for example, adopting finned surface to increase effective heat dissipation area (Huang et al 2008; Yu et al 2010), using perforated or stripped fin to damage boundary layer to intensify heat transfer (Wang et al 1998; Kang \& Kim 1999), and optimizing fin shape and dimensions to form better flow pattern for heat transfer (Baskaya et al 2000). It should be noted that current research mainly focuses on heat radiator. In fact, heat sink, substrate, and lampshade together form the whole heat dissipation structure of LED lamp. Even though the substrate and lampshade contribute little effective heat transfer area, they are crucial for forming a beneficial flow pattern to heat transfer.

The whole heat dissipation structure of LED lamp is taken as the research object in this paper. Based on CFD (computational fluid dynamics) principle, a three-dimensional mathematical model including LED chips, MCPCB (metal core printed circuit board), heat sink, lampshade and exterior surrounding air is established. Then the mathematical model is numerically solved to simulate the natural convection heat transfer process. Based on the analysis of flow and heat transfer characteristics, boring through-hole is utilized to improve the heat dissipation structure. Analysis based on field synergy principle indicates that the through-hole has improved the synergy between flow field and temperature field, and intensified the heat transfer under natural convection.

\section{Mathematical modelling}

The schematic drawing of the LED luminaries under investigation is shown in figure 1. The luminaries are composed of heat sink, MCPCB, LED chips and lampshade. The origin of coordinates is located in the center of the base of heat sink. The thicknesses at $\mathrm{z}$ direction of Lampshade, MCPCB and base are $4 \mathrm{~mm}, 1.5 \mathrm{~mm}$ and $10 \mathrm{~mm}$, respectively. All of them have the same dimension at both $\mathrm{x}$ and $\mathrm{y}$ as $0.157 \mathrm{~m}(\mathrm{x})$ and $0.123 \mathrm{~mm}(\mathrm{y})$. The heat sink of plate-fin type is $50 \mathrm{~mm}$ in fin height, $10 \mathrm{~mm}$ in fin spacing, and $3 \mathrm{~mm}$ in fin thickness. The heat sink is made of aluminum alloy. LED Chips distributed on the MCPCB are divided into 4 groups. Each group occupies an area of $40 \mathrm{~mm}$ long and $30 \mathrm{~mm}$ wide, where six chips are arranged in two rows. Each LED 


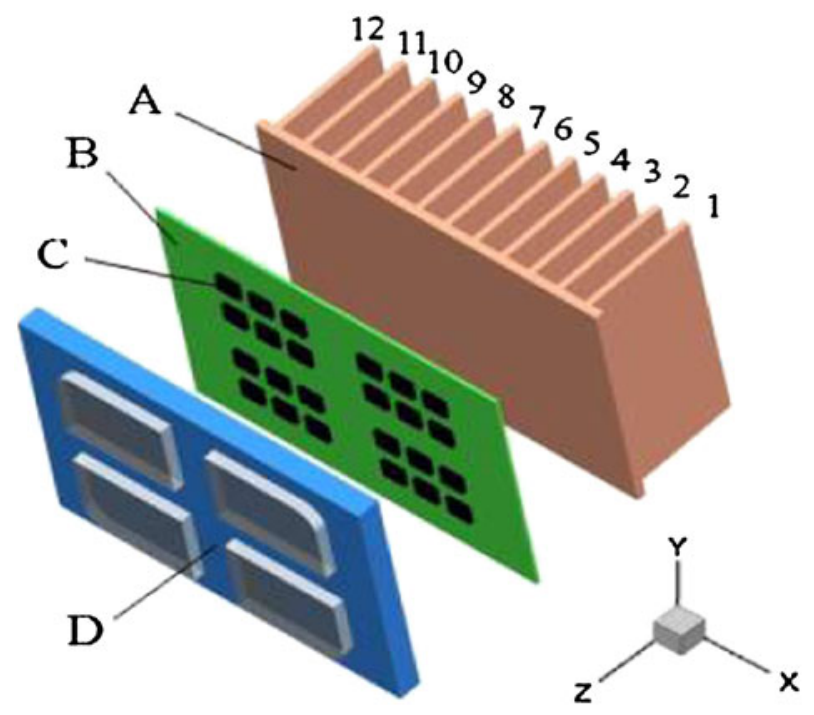

Figure 1. Diagram of LED structure (A-heat sink; B-MCPCB; C-LED chip; D-lampshade).

chip has an input power of $1.25 \mathrm{~W}$ and its efficiency of photoelectric conversion is around $20 \%$, which means that $1 \mathrm{~W}$ heat is generated in each chip.

Material properties of the LED luminaries are shown in table 1. The computational domain is $1.0 \mathrm{~m}^{3}$ including exterior air flow field and LED luminaries. The LED luminaries are located in the middle of computational domain. Turbulence natural convection and radiation are described as the main mechanisms of heat transfer in the present mathematical model.

\subsection{Governing equations}

The heat dissipation process modelled by a set of partial differential equations in threedimensional Cartesian coordinate directions is as follows.

Mass conservation equation:

$$
\frac{\partial \rho}{\partial \mathrm{t}}+\frac{\partial\left(\rho u_{i}\right)}{\partial x_{i}}=0
$$

Momentum conservation equations

$$
\frac{\partial \rho \mathrm{u}_{i}}{\partial t}+\frac{\partial}{\partial x_{j}}\left(\rho u_{i} u_{j}\right)=-\frac{\partial p}{\partial x_{i}}+\frac{\partial}{\partial x_{j}}\left(\mu \frac{\partial u_{i}}{\partial x_{j}}-\rho \overline{u_{i}^{\prime} u_{j}^{\prime}}\right)+\rho g_{i} .
$$

Table 1. Material properties.

\begin{tabular}{lcccc}
\hline & $\begin{array}{c}\text { Density/ } \\
\mathrm{kg} \cdot \mathrm{m}^{-3}\end{array}$ & $\begin{array}{c}\text { Thermal conductivity/ } \\
\mathrm{w} \cdot \mathrm{m}^{-1} \cdot \mathrm{k}^{-1}\end{array}$ & $\begin{array}{c}\text { Specific heat capacity/ } \\
\mathrm{J} \cdot \mathrm{kg}^{-1} \cdot \mathrm{k}^{-1}\end{array}$ & Emissivity \\
\hline Heat $\operatorname{sink}$ & 2719 & 201 & 871 & 0.15 \\
MCPCB & 935 & 2 & 2300 & 0.9 \\
Lampshade & 1140 & 0.22 & 1503.6 & 0.9 \\
\hline
\end{tabular}


$\mathrm{k}$ transport equation

$$
\frac{\partial}{\partial t}(\rho k)+\frac{\partial}{\partial x_{i}}\left(\rho k u_{i}\right)=\frac{\partial}{\partial x_{j}}\left[\left(\mu+\mu_{t} / \sigma_{k}\right) \frac{\partial k}{\partial x_{j}}\right]+G_{k}+G_{b}-\rho \varepsilon .
$$

$\varepsilon$ transport equation

$$
\frac{\partial}{\partial}(\rho \varepsilon)+\frac{\partial}{\partial \mathbf{x}_{i}}\left(\rho \varepsilon \mu_{i}\right)=\frac{\partial}{\partial x_{j}}\left[\left(\mu+\frac{u_{t}}{\sigma_{\varepsilon}}\right) \frac{\partial \varepsilon}{\partial x_{j}}\right]+C_{1 \varepsilon} \frac{\varepsilon}{k}\left(G_{k}+C_{3_{\varepsilon}} G_{b}\right)-C_{2 \varepsilon} \rho \frac{\varepsilon^{2}}{k} .
$$

Energy conservation equation

$$
\frac{\partial}{\partial t}(\rho E)+\frac{\partial}{\partial x_{j}}\left[u_{i}(\rho E+p)\right]=\frac{\partial}{\partial x_{j}}\left(\frac{k_{\mathrm{eff}} \partial T}{\partial x_{j}}\right)+\rho Q_{R} .
$$

Radiative transfer equation

$$
\frac{\partial}{\partial \mathrm{x}_{j}}\left(\Gamma \frac{\partial G}{\partial x_{j}}\right)-\alpha \mathrm{G}+4 \alpha \sigma \mathrm{T}^{4}=0,
$$

where, $-\rho \overline{\mathrm{u}_{\mathrm{i}}^{\prime} \mathrm{u}_{j}^{\prime}}=u\left(\frac{\partial u_{i}}{\partial x_{j}}+\frac{\partial u_{j}}{\partial x_{i}}\right)-\frac{2}{3} \rho k \delta_{i j}$ is Reynolds stress tensor.

The assumptions employed in the model conform to compressible, turbulence flow of air. Air is assumed as the ideal gas.

\subsection{Solution method and boundary conditions}

The numerical model is based on a control volume finite difference formulation. Momentum equation is discretized by second order upstream scheme, density and energy equations are both discretized by first order up wind scheme. The discretized equations are solved by SIMPLE algorithm (Patankar 1980). The convergence criterion of the numerical solution is based on the absolute normalized residuals of the equations. Convergence is considered as being achieved when these residuals become less than $10^{-3}$. The whole domain is meshed by non-uniform hexahedral grids, and the number of cells is about $1.2 \times 10^{7}$. Grids in the areas of chips and small gaps between fins are refined.

The no-slip condition is applied on the wall and the wall functions are used at the near wall domain. The thermal contact resistance along the chip, substrate and radiator is neglected. Wallsurface is coupled at the interface between fluid region and solid region to realize the heat transfer between the heat radiator and the exterior air space. The Neumann boundary condition is applied on the surfaces of LED chips which are fixed on MCPCB. Exterior space is of open boundary condition, which maintains the pressure and temperature at $1.01 \times 10^{5} \mathrm{~Pa}$ and $27^{\circ} \mathrm{C}$, respectively.

\section{Analysis of the computational results}

\subsection{Computational analysis on previous heat radiator}

Figures 2 and 3 show velocity distributions of air flow in the plane of $y=0 \mathrm{~m}, \mathrm{x}=0 \mathrm{~m}$, respectively. As shown in figures 2 and 3, air near solid surface is heated and moves upwards 


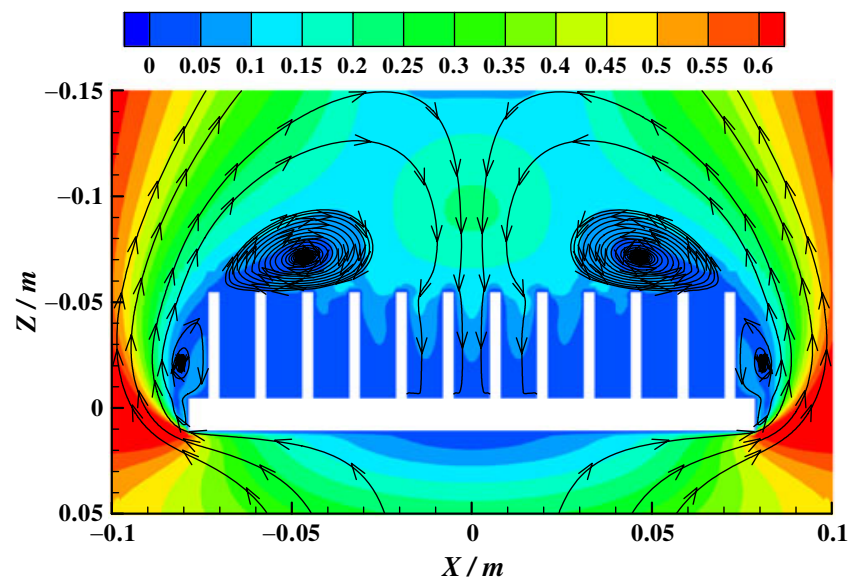

Figure 2. Velocity vector of $\mathrm{y}=0 \mathrm{~m}$ plane.

as a result of buoyancy effect. To keep the continuity of flow field, cold air flows upwards from the bottom. This results in a bottom-up natural convection. After the warm air rises to a certain height, it is cooled down and the buoyancy effect weakens, then it goes down into the gap space between fins, and thus forms two symmetric circumfluences as shown in figure 2. Since the fin spacing is small, air flow that flows upwards along the edge of base can hardly enter the gap space between fins because of large flow resistance, while air flow entering the gap space from the top is able to flow outwards to external space and then rise up with exterior flow, as shown in figure 3 .

From the heat transfer enhancement point of view, this air flow pattern has two obvious problems. Firstly, there are two local circumfluence above the fins, which is harmful for heat transfer. As shown in figure 4, the convection heat transfer coefficient of the fins (No. 2, 3) under the circumfluence is much smaller elsewhere than that. And the average heat transfer coefficient of the

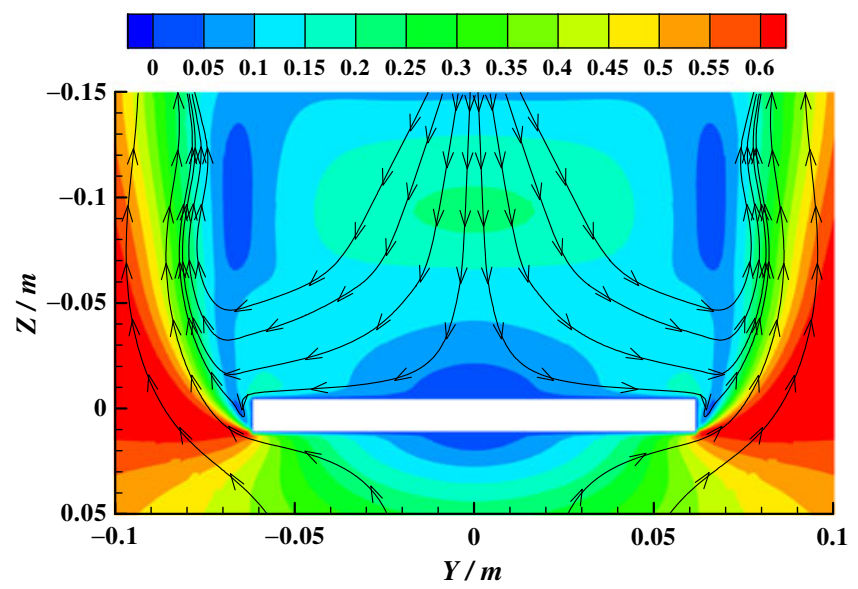

Figure 3. Velocity vector of $\mathrm{x}=0 \mathrm{~m}$ plane. 


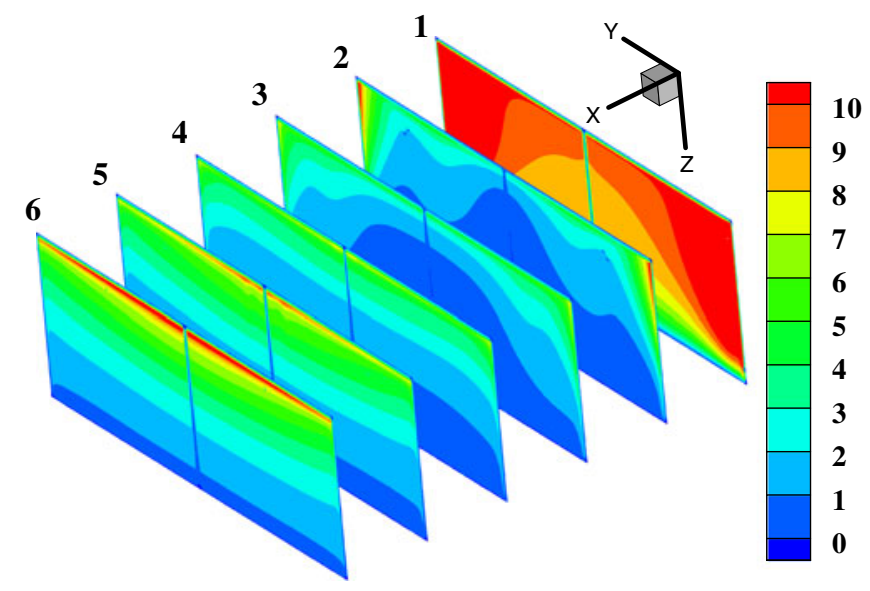

Figure 4. Heat transfer coefficient distribution of fin surface.

whole fin surfaces is $3.60 \mathrm{~W} \cdot \mathrm{m}^{-2} \cdot \mathrm{K}^{-1}$. Secondly, the coordination of velocity and heat flow field is poor. According to the field synergy principle (Guo et al 1998), the convective heat transfer is attributed not only to temperature difference, fluid velocity and fluid properties, but also to the match level of velocity and heat flow fields. The smaller the intersection angle between velocity and heat flow fields, the better is the heat transfer. When the streamline and the isothermal line are quadrature, which means the velocity and heat flow vector are parallel, the highest heat transfer rate is obtained. From figures 3 and 4, it is found that the air flow between fins moves from top to bottom, and blows the bottom walls, which thickens the boundary layer and weaken the heat transfer. Meanwhile, from the coordination of velocity and heat flow field, as shown in figure 5, the velocity and heat flow vector are quadrature only in a small area of fins, and the average intersection angle between them are $47.5^{\circ}$.

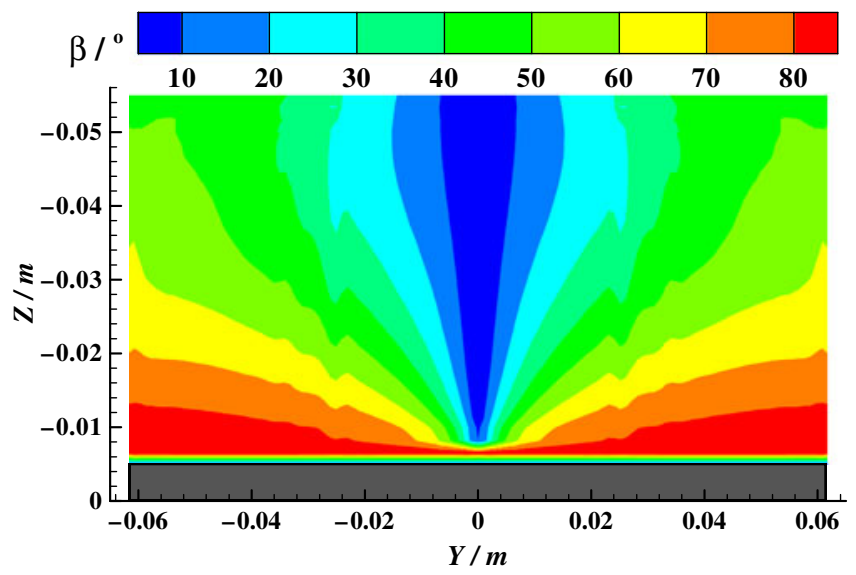

Figure 5. Coordination of velocity and heat flow field. 


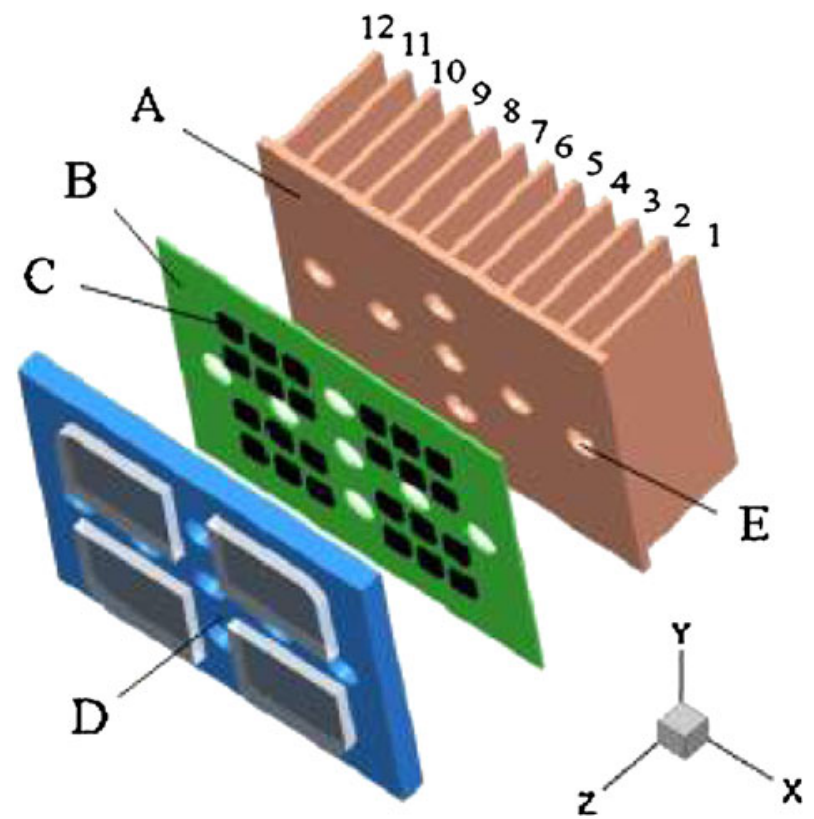

Figure 6. Diagram of improved LED structure (A-heat sink; B-MCPCB; C-LED chip; D-lampshade, E-hole).

\subsection{Improvement of heat dissipation structure}

The before-mentioned analysis shows clearly that the flow pattern of exterior air has significant effect on the heat dissipation of LED luminaries. Under natural convection condition, the flow pattern of exterior air is mainly determined by the heat dissipation structure of LED luminaries. Therefore, the heat dissipation of LEDs can be intensified by improving the luminaries-level

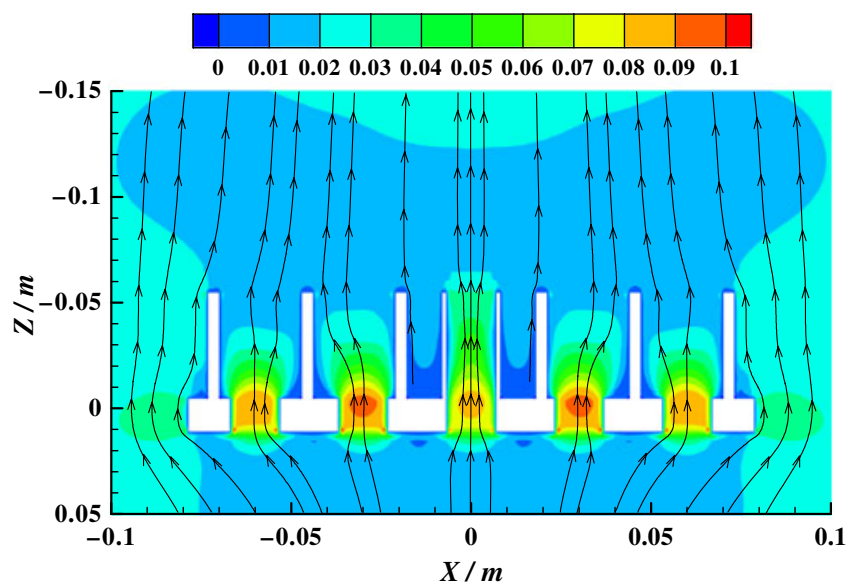

Figure 7. Velocity vector of $\mathrm{y}=0 \mathrm{~m}$ plane after improvement. 


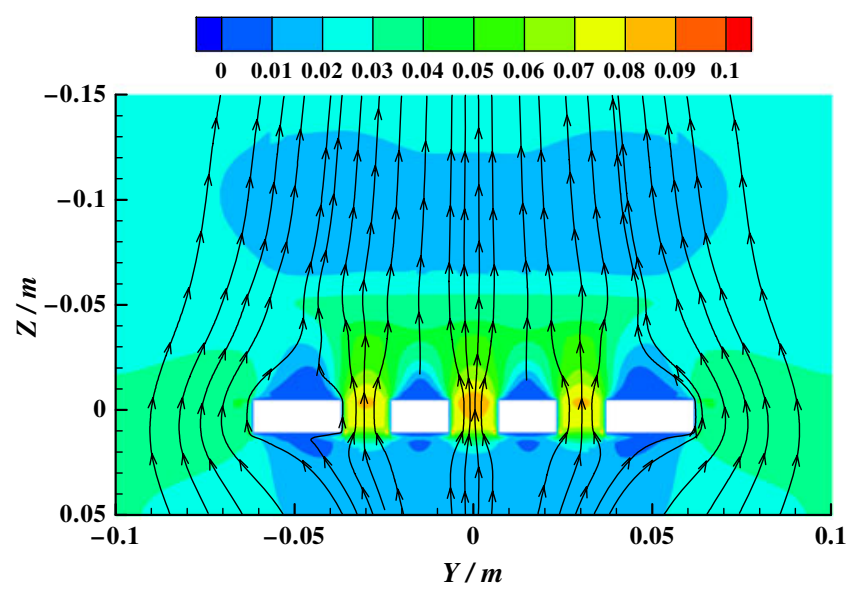

Figure 8. Velocity vector of $\mathrm{x}=0 \mathrm{~m}$ plane after improvement.

structure to form a more reasonable flow field. Based on field synergy analysis, through-holes are used to improve the LEDs' heat dissipation structure. As shown in figure 6, seven through-holes are distributed along both $\mathrm{x}$ axis and $\mathrm{y}$ axis. The diameter of the hole and the spacing between two adjacent holes are $14 \mathrm{~mm}$ and $30 \mathrm{~mm}$, respectively. The holes cross fins, the base of heat sink, MCPCB, and lampshade.

Figures 7 and 8 present velocity distributions of air flow after improvement in the plane of $\mathrm{y}=0 \mathrm{~m}, \mathrm{x}=0 \mathrm{~m}$, respectively. Compared with the flow pattern before improvement, as shown in figures 2 and 3, the flow field structure of the improved model is much simpler and has the characteristic of one-way flow. That is, the surrounding air almost always moves from bottom to top and the local circumfluence on the top of fins is eliminated. Therefore the adverse effects of stationary air are avoided. Meanwhile, the local flow direction of areas between fins are also bottom to top, the air enters the fin region from the holes of the bottom and the two open ends,

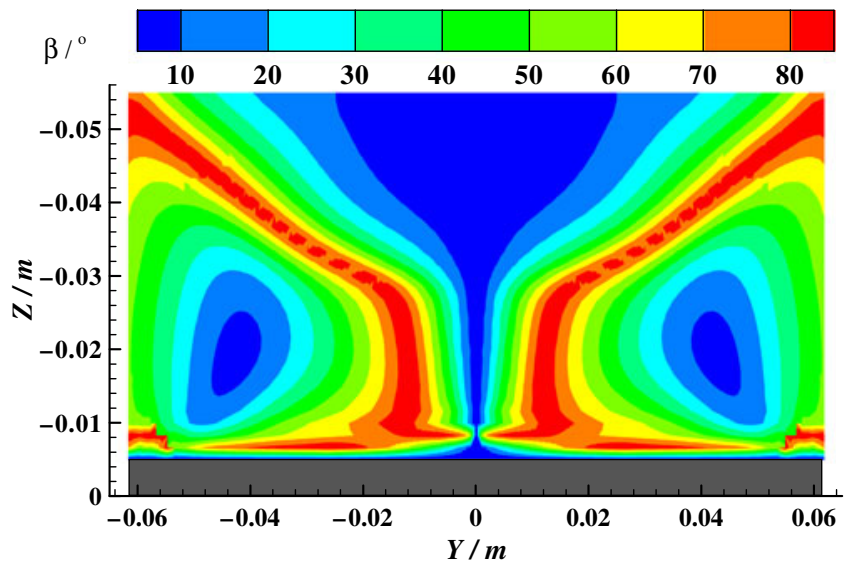

Figure 9. Coordination of velocity and heat flow field after improvement. 


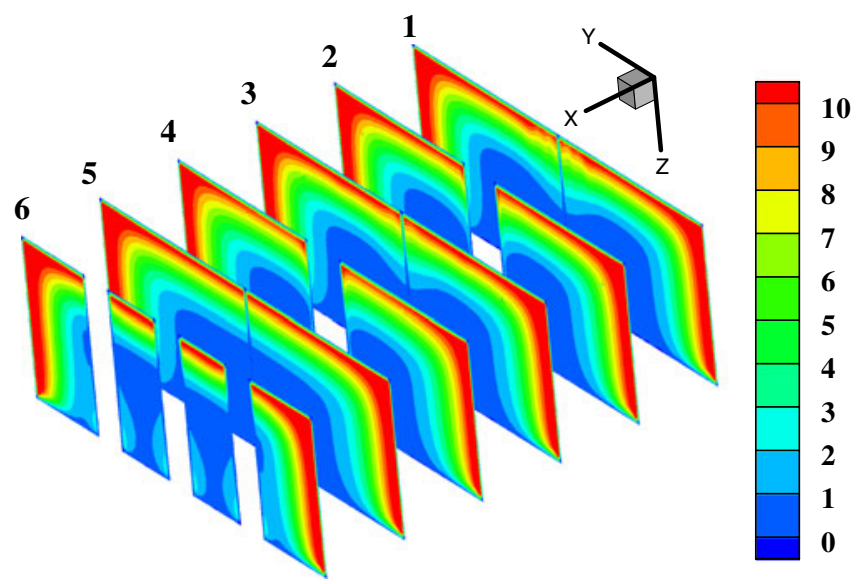

Figure 10. Heat transfer coefficient distribution of fin surface after improvement.

moves upward and then escapes (goes up and away) from the top of the fins. The flow direction of the improved model is opposite to the unimproved model. The suction flow is formed under the improved structure, and the thickness of boundary layer is decreased. The heat transfer is further enhanced. By comparing figure 5 with figure 9, it is shown that the field synergy is improved, and the average intersection angle between velocity and heat flow field reduces to $38.3^{\circ}$.

Figure 10 shows the heat transfer coefficient distribution after improvement. The homogeneous air flow leads the heat transfer coefficient of fin surface to be uniform. Therefore, the heat transfer performance of each fin is fully used, and the average heat transfer coefficient of fin surface reaches $5.25 \mathrm{~W} \cdot \mathrm{m}^{-2} \cdot \mathrm{K}^{-1}$. Compared with the unimproved model, the average heat transfer coefficient of fin's surface increases by $45.8 \%$ and the highest temperature of heat radiator decreases by about $8{ }^{\circ} \mathrm{C}$. It shows that boring through-hole can optimize the flow pattern, and then reduce the intersection angle between velocity and heat flow field under natural convection. So the heat dissipation of the LEDs is enhanced dramatically.

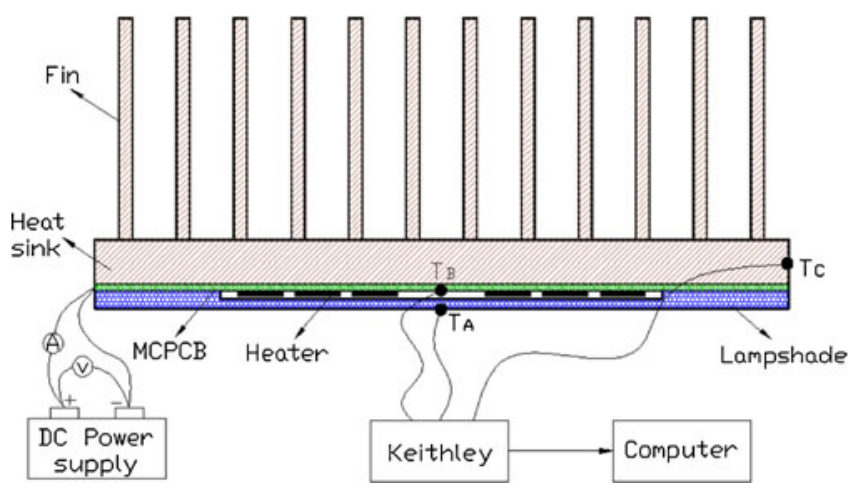

Figure 11. The test apparatus. 


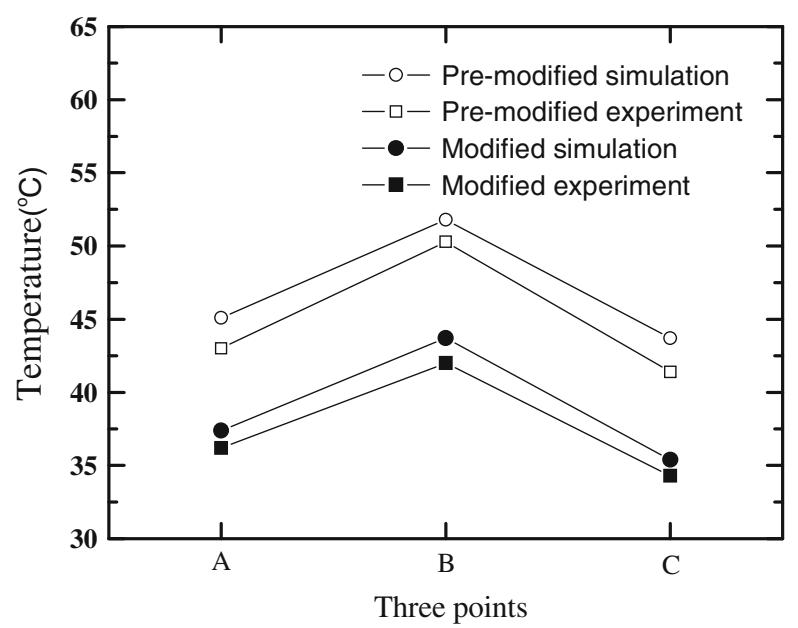

Figure 12. Comparison of temperature on the test points between computational and experimental method.

\section{Verification of the models}

To verify the accuracy of these two models, experiments were carried out in a hermetic room which is about $3.5 \mathrm{~m}$ high with an area of $25 \mathrm{~m}^{2}$. Room temperature was controlled by an air conditioner. Precautions such as turning off the room ventilators and closing all doors were taken to minimize extraneous air-current effects. The test apparatus is shown in figure 11. A copperconstantan thermocouple was set near the LED luminaries to monitor environment temperature. Several PT100 thermometers were installed at the center of lampshade, MCPCB and at boundaries of base of heat radiator. The holes were slightly larger than the PT100 diameters and the gaps between them were filled with the thermal silica to make sure a good thermal contact. When the air conditioner was working to keep room temperature at $27^{\circ} \mathrm{C}$ for $30 \mathrm{~min}$, LED chips started to work. During the course of a run, instrument readings were taken at 10 min intervals. A steady state was deemed to exist when identical readings were obtained for an hour period. Temperature data at three points of lampshade, MCPCB and the base of heat radiator were respectively collected to be compared with computational results. The coordinates of these three points are A $(0,0,0.009), \mathrm{B}(0,0,0.0065), \mathrm{C}(0.078,0,0.005)$, respectively. As shown in figure 12 , numerical results agree well with experimental data, with a deviation less than $5 \%$. It is also seen that the temperatures of the improved model are decreased by about $8^{\circ} \mathrm{C}$ comparing to the unimproved model. It indicates that the thermal resistance of the LED is reduced.

\section{Conclusions}

In order to broaden the application of LEDs, it is important to improve the heat dissipation performance of LED luminaries. In this paper, the temperature distribution of LED luminaries and the flow pattern of the complex exterior natural convection are studied based on CFD method as well as the physical experiment. As shown, the flow pattern of exterior air is one of the most important factors that influence the heat dissipation performance of LED luminaries. Under natural 
convection condition, the flow pattern of exterior air is mainly determined by the heat dissipation structure of LED luminaries. Based on field synergy analysis, method of boring through-holes is adopted to improve the LEDs' heat dissipation structure and the flow pattern of exterior air flow in order to improve the coordination of velocity and heat flow field and intensify heat dissipation. Under present computational conditions, by luminaries-level structure improvement the highest temperature of fins is reduced by $8^{\circ} \mathrm{C}$ and overall heat transfer coefficient is increased by $45.8 \%$.

\section{Acknowledgements}

The authors thank the National Natural Science Foundation of China (No. 61154002), the Zhejiang Provincial Natural Science Foundation of China (No.Z1110222), and the project named 'Research on Key Technology of Large-span Municipal Tunnel Construction and Operation under Complicated Environment' for support.

\section{Nomenclature}

C Linear-anisotropic phase function coefficient

$C_{1 \varepsilon} \quad$ Model constants $\mathrm{C}_{1 \varepsilon}=1.44$

$C_{2 \varepsilon} \quad$ Model constants $\mathrm{C}_{2 \varepsilon}=1.92$

$C_{3 \varepsilon} \quad$ Model constants $\mathrm{C}_{3 \varepsilon}=0.8$

$C_{\mu} \quad$ Model constants $\mathrm{C}_{\mu}=0.09$

E $\quad E=H-p / \rho+u^{2} / 2$

$g \quad$ Acceleration of gravity $\left(\mathrm{m} \mathrm{s}^{-2}\right)$

$G \quad$ Incident radiation

$G_{b} \quad$ The generation of turbulence kinetic due to buoyancy, $G_{b}=-\frac{\mu_{t} g_{i}}{\rho \operatorname{Pr}_{t}} \frac{\partial \rho}{\partial x_{i}}$

$G_{k} \quad$ The generation of turbulence kinetic due to mean velocity gradients, $G_{k}=-\rho \overline{u_{i}^{\prime} u_{j}^{\prime}} \frac{\partial u_{j}}{\partial x_{i}}$

$h \quad$ Heat transfer coefficient $\left(\mathrm{W} \mathrm{m}^{-2} \mathrm{~K}^{-1}\right)$

$H \quad$ Enthalpy $\left(\mathrm{J} \mathrm{kg}^{-1}\right)$

$k \quad$ Turbulence kinetic energy $\left(\mathrm{m}^{2} \mathrm{~s}^{-2}\right)$

$k_{\text {eff }} \quad$ Effective thermal conductivity $\left(\mathrm{W} \mathrm{m}^{-1} \mathrm{~K}^{-1}\right)$

$p \quad$ Static pressure $(\mathrm{Pa})$

$\operatorname{Pr}_{t} \quad$ Turbulent Prandtl number for energy $\operatorname{Pr}_{t}=0.85$

$Q_{R} \quad$ Radiation flux $\left(\mathrm{w} \mathrm{m}^{-3}\right), Q_{R}=-\Gamma \nabla G$

$t \quad$ Time(s)

$T \quad$ Temperature(K)

$\mu \quad \operatorname{Velocity}\left(\mathrm{m} \mathrm{s}^{-1}\right)$

\section{Greek Symbols}
$\alpha \quad$ Absorption coefficient
$\beta \quad$ Intersection angle between velocity and heat flow field, degree
$\rho \quad \operatorname{Density}\left(\mathrm{kg} \mathrm{m}^{-3}\right)$
$\mu \quad \operatorname{Viscosity}\left(\mathrm{kg} \mathrm{m}^{-1} \mathrm{~s}^{-1}\right)$ 
$\mu_{t} \quad$ Turbulent viscosity $\mu_{t}=C_{\mu} k^{2} / \varepsilon$

$\varepsilon \quad$ Turbulence dissipation $\operatorname{rate}\left(\mathrm{m}^{2} \mathrm{~s}^{-3}\right)$

$\sigma_{k} \quad$ Model constants $\sigma_{k}=1.0$

$\sigma_{\varepsilon} \quad$ Model constants $\sigma_{\varepsilon}=1.3$

$\sigma_{s} \quad$ Scattering coefficient

$\Gamma \quad$ Model parameter, $\Gamma=1 /\left(3\left(\alpha+\sigma_{s}\right)-C \sigma_{s}\right)$

\section{References}

Acikalin T, Garimella SV, Petroski J and Raman A 2004 Optimal design of miniature piezoelectric fans for cooling light emitting diodes. 9th Intersociety Conference on Thermal and Thermo mechanical Phenomena in Electronic Systems, Las Vegas, NV, 663-671

Arik M, Setlur A, Weaver S, Haitko D and Petroski J 2007 Chip to system levels thermal needs and alternative thermal technologies for high brightness LEDS. J. Electron Packaging. 129(3): 328-338

Baskaya S, Sivrioglu M and Ozek M 2000 Parametric study of natural convection heat transfer from horizontal rectangular fin arrays. Int J. Therm. Sci. 39(8): 797-805

Guo Z Y, Li D Y and Wang B X 1998 A novel concept for convective heat transfer enhancement. Int. J. Heat Mass Transfer. 41(14): 2221-2225

Huang R T, Sheu W J and Wang C C 2008 Orientation effect on natural convective performance of square pin fin heat sinks. Int. J. Heat Mass Transfer. 51(9-10): 2368-2376

Kang H C and Kim M H 1999 Effect of strip location on the air-side pressure drop and heat transfer in strip fin-and-tube heat exchanger. Int. J. Refrig. 22(4): 302-312

Luo X B, Liu S, Jiang X P and Cheng T 2007 Experimental and numerical study on a micro jet cooling solution for high power LEDs. Sci. China, Ser. E. 50(4): 478-489

Patankar S V 1980 Numerical heat transfer and fluid flow. New York, USA: McGraw-Hill Book Co

Schubert E F and Kim J K 2005 Solid-state light sources getting smart. Science 308(5726): 1274-1278

Wang C C, Chi K Y, Chang Y J and et al 1998 An experimental study of heat transfer and friction characteristics of typical louver fin-and-tube heat exchangers. Int. J. Heat Mass Transfer. 41(4-5): $817-822$

Yu S H, Lee K S and Yook S J 2010 Natural convection around a radial heat sink. Int. J. Heat Mass Transfer. 53(13-14): 2935-2938 